\title{
Exploring Factors Influencing Perinatal Outcomes among Adolescent Pregnancies in Northern Ghana-The Case of Kassena-Nankana Municipality in the Upper East Region.
}

\author{
Matthew Naakiyab Laari ${ }^{1 *}$, Alexander Suuk Laar² \\ ${ }^{1 *} \mathrm{MPH}$ (Population \& Reproductive Health), Community Health Nurses' Training College, \\ Navrongo, Ministry of Health, Ghana. \\ 2MPH (Health Economics), c/o PATH-Ghana, PMB CT 307, Cantonments, Accra, Ghana.
}

\begin{abstract}
Introduction: It is estimated that about $11 \%$ of births worldwide are to adolescents aged 15-19 years, and more than $90 \%$ of these births occur in low and middle-income countries with an increased risk of adverse pregnancy outcomes such as perinatal mortality.

Aims and Objectives: The purpose of the study was to explore the factors that influence perinatal outcomes in adolescent pregnancies.

Materials and Methods: A facility-based cross-sectional study with 200 adolescent mothers who delivered. Multistage sampling method was used to select the facilities. Simple random sampling technique was used to select the participants at the facilities. The data were analysed using STATA version 11 software programme.

Results: The majority of the participants $(71 \%)$ were between 18-19 years. Perinatal mortality rate was 30 per 1000 births. The following were found to be associated with high perinatal mortality rate: gestational age less than 37 weeks, harmful traditional practices, mothers who never used family planning service. Also, mothers who consumed alcohol had a highest odds of 5.9 perinatal mortality compared to other predictors. The results also showed that women living in a rural area $\{O R=0.41,95 \% \mathrm{Cl}(0.1-2.3)\}$ and those delivering at home $\{\mathrm{OR}=3.91,95 \% \mathrm{Cl}(0.6-22.5\}$ were more likely to experience adverse perinatal outcomes. Finally, perinatal mortality rate (33 per 1000 births) among the mothers aged between 15 and 17
\end{abstract}

\section{INTRODUCTION}

It is estimated that about $11 \%$ of births world- wide are to adolescents aged 15-19 years, and more than $90 \%$ of these births occur in low- and middle-income countries ${ }^{1,2}$ with an increased risk of adverse pregnancy outcomes such as preterm birth and perinatal death associated with adolescence pregnancy. ${ }^{3-5}$ According to $\mathrm{WHO}, 7.3$ million of perinatal deaths that take place annually, 7 million of these deaths occur in developing countries, of which it is estimated that between 40 and $50 \%$ occur during the first seven days of life. Adverse perinatal outcomes pose a public health challenge to the health status and development of the society. ${ }^{6}$ More than $99 \%$ of perinatal mortality that occur in developing countries especially in sub- Saharan years appears high compared to between 18 and 19 years category (28 per 1000 births).

Conclusion: The results reported in this study indicate that mothers who engaged in harmful traditional practices, had less than 37weeks gestation, used alcohol during pregnancy and never used family planning services prior to their pregnancies had increased odds of experiencing perinatal mortality. The combined effect of these factors needs to be taken into account when counseling women about healthy behaviour before and during pregnancy at health facilities.

Key words: Adolescent pregnancies, Perinatal outcomes, Neonatal death, Stillbirth, Ghana.

\section{${ }^{*}$ Correspondence to:}

Mathew Naakiyab Laari

Community Health Nurses' Training College,

P.0.185, Navrongo-UER, Ghana.

Article History:

Received: 21-08-2016, Revised: 11-09-2016, Accepted: 20-09-2016

\begin{tabular}{|l|c|}
\hline \multicolumn{2}{|c|}{ Access this article online } \\
\hline $\begin{array}{l}\text { Website: } \\
\text { www.ijmrp.com }\end{array}$ & \\
\hline DOI: & \\
10.21276/ijmrp.2016.2.5.015 & \\
\hline
\end{tabular}

Africa $^{2}$ at a predictable average rate of 57 per 1000 live births worldwide are preventable. Perinatal outcomes including live births, stillbirths and early neonatal deaths among adolescent pregnancies are particularly important determinants of infant mortality and morbidity in life.

Adolescent pregnancy continues to be a major social concern. A true burden of perinatal outcomes in adolescent pregnancies needs to be understood and further addressed. To help revitalize efforts to reduce child and newborn deaths and to contribute towards achieving the Sustainable Development Goals 2030, this study explored the causes of perinatal outcomes among adolescent mothers in northern Ghana. 


\section{MATERIALS AND METHODS}

\section{Study area}

The Kassena-Nankana Municipality is one of the nine (9) Districts/municipalities located in the Upper East Region of Ghana. It spreads from 55 kilometers from north to south and 53 kilometers from east to west. The municipality shares boundaries to the: North with Kassena-Nankana West District and Burkina Faso, East with Kassena-Nankana West District and Bolgatanga Municipality, West with the Builsa District and South with West Mamprusi District (in the Northern Region). The Municipal's capital is Navrongo. The Municipality is made up of seven submunicipalities. For this study, five sub municipalities were sampled. The proportion of women in their reproductive age is $24 \%$. There are an estimated 24 health facilities in the Municipality. These are 1 Municipal Hospital, 2 Health Centres, 1Private Clinic, 1CHAG facility and 19 functioning CHPS.

\section{Research design}

A facility-based cross-sectional study with 200 adolescent mothers who delivered were interviewed.

\section{Data collection}

Quantitative data collection technique using structured interviews was employed. All mothers who were adolescents and delivered within the study period from October 2011 to September 2013 were interviewed. The data was collected from participants during antenatal and child welfare clinics.

\section{Inclusion criteria}

The study participants comprised of adolescent mothers between the ages of 15-19years, who were residents in the Municipality for the last two years and with history of singleton births. Adolescent mothers who did not meet the criteria were excluded.

\section{Data analysis}

Data were processed and analysed using statistical software STATA version 11. The multiple choice and dichotomous responses were converted to percentages. Association between independent variables and the dependent variable were measured with odds ratio. The observed association between independent variables and the dependent variable (perinatal outcomes) were tested for statistical significance using chi square test. To understand how these variables influence perinatal outcomes upon interaction, further analysis was done using binary logistic regression. $P<0.05$ was assumed to be significant.

\section{Ethical considerations}

The proposal was approved by Committee on Human Research, Publications and Ethics of the Kwame Nkrumah University of Science and Technology (KNUST).Informed consent was obtained from the participants and head of the health institutions and community leaders.

\section{RESULTS}

Socio-demographic characteristics of Mothers

All the 200 mothers for this survey had singleton births with six experiencing perinatal mortality. Most (59\%) were married. The ages of mothers at delivery ranged from $15-19$ years with majority

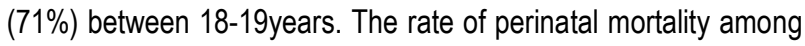
women between 15 and 17 years was 33 per 1000 births compared to between 18 and 19 years age group of 28/1000births. More of the perinatal cases (30 per 1000 births) occurred among adolescent rural mothers compared to urban mothers (28 per 1000 births).

Over eighty percent $(84 \%)$ of the women had formal education. Majority $(87 \%)$ delivered at 9 calender months or greater. Perinatal death among the mothers who delivered more than once was 73 per 1000 births.

The findings further showed that there was statistical association between perinatal mortality and gestational age less than 37 weeks (136 per 1000 births).(Table 1)

Table 1: Association of Socio-demographic factors of Mothers with perinatal outcomes.

\begin{tabular}{lccc}
\hline Socio-demographic characteristics & $\begin{array}{c}\text { Total births } \\
\text { N (200(\%) }\end{array}$ & $\begin{array}{c}\text { Perinatal deaths } \\
\text { (PNM/1000births) }\end{array}$ & $\begin{array}{c}\text { P- value } \\
\text { (95\% Cl) }\end{array}$ \\
\hline Maternal age(years) & $59(29)$ & $2(33)$ & \\
$15-17$ & $141(71)$ & $4(28)$ & $\mathrm{P}=0.834$ \\
$18-19$ & & & \\
Residence & $165(83)$ & $5(30)$ & $\mathrm{P}=0.300$ \\
Rural & $35(17)$ & $1(28)$ & \\
Urban & $118(59)$ & $4(33)$ & \\
Marital status & $57(27)$ & $2(35)$ & \\
Married & $11(5)$ & & \\
Single & $14(7)$ & & \\
Divorced/Separated & & & \\
Living with partner & $31(16)$ & $2(64)$ & \\
Level of education & $152(76)$ & $3(19)$ & \\
No formal education & $17(8)$ & $1(58)$ & \\
Primary & & & \\
Secondary/Tertiary & $159(80)$ & $3(19)$ & \\
Parity & $41(20)$ & $3(73)$ & \\
Nulliparous & & & \\
Multiparous & $18(9)$ & $2(133)$ & \\
Birth interval & $175(88)$ & $4(27)$ & \\
$<24$ months & $7(3)$ & $3(136)$ & \\
$\geq 24 m o n t h s$ & & $3(17)$ & \\
Don't remember & $22(11)$ & & \\
Gestation & $174(87)$ & & \\
$<37$ weeks & $4(2)$ & & \\
$\geq 37$ weeks & & & \\
Don't remember & & & \\
\hline
\end{tabular}


Table 2: The association of health behaviours and health care utilization with perinatal outcomes.

\begin{tabular}{|c|c|c|c|c|}
\hline Category & $\begin{array}{l}\text { Total Births } \\
\text { No }(\%)\end{array}$ & $\begin{array}{l}\text { Perinatal deaths } \\
\text { (PNM/ 1000births) }\end{array}$ & $\begin{array}{l}\text { Odds ratio } \\
(95 \% \mathrm{Cl})\end{array}$ & $\begin{array}{l}\text { Adjusted odds } \\
\text { ratio }(95 \% \mathrm{Cl})\end{array}$ \\
\hline Maternal age(years) & \multicolumn{4}{|c|}{$\mathrm{P}=0.8$} \\
\hline $15-17$ & $59(29)$ & $2(33)$ & 1 & \\
\hline $18-19$ & $141(71)$ & $4(28)$ & $0.8(0.1-4.7)$ & \\
\hline Residence & \multicolumn{4}{|c|}{$\mathrm{P}=0.3$} \\
\hline Rural & $165(83)$ & $5(30)$ & $0.41(0.1-2.3)$ & \\
\hline Urban & $35(17)$ & $1(28)$ & 1 & \\
\hline Birth interval & \multicolumn{4}{|c|}{$P=0.0$} \\
\hline$<24$ months & $18(9)$ & $2(111)$ & 1 & \\
\hline$\geq 24$ months & $175(88)$ & $4(23)$ & $0.2(0.0-1.1)$ & \\
\hline Don't remember & $7(3)$ & & & \\
\hline Gestation & & $P<0.0$ & $P<0.0$ & \\
\hline$<37$ weeks & $22(11)$ & $3(136)$ & 1 & 1 \\
\hline$\geq 37$ weeks & $174(87)$ & $3(17)$ & $0.11(0.0-0.5)$ & $1.7(1.1-2.2)$ \\
\hline Don't remember & $4(2)$ & & & \\
\hline Traditional beliefs and practices & & $P<0.0$ & $P=0.0$ & \\
\hline Yes & $33(16)$ & $3(90)$ & $5.46(1.1-28.4)$ & $1.4(0.1-14.8)$ \\
\hline No & $167(84)$ & $3(17)$ & 1 & \\
\hline Mothers medical condition & \multicolumn{4}{|c|}{$P=0.835$} \\
\hline Yes & $53(26)$ & $3(56)$ & $2.88(0.57-14.7)$ & \\
\hline No & $147(74)$ & $3(20)$ & 1 & \\
\hline Alcohol use during pregnancy & & $P<0.0$ & $P=0.2$ & \\
\hline Yes & $17(8)$ & $2(125)$ & $5.96(1.01-35.3)$ & $4.9(0.4-65.0)$ \\
\hline No & 183(92) & $4(21)$ & 1 & \\
\hline Used any family planning method & & $P<0.0$ & $P<0.0$ & \\
\hline Yes & 148(74) & $4(13)$ & 1 & 1 \\
\hline No & $52(26)$ & $2(76)$ & $0.2(0.0-0.9)$ & $1.2(0.0-0.7)$ \\
\hline Place of delivery & \multicolumn{4}{|c|}{$\mathrm{P}=0.1$} \\
\hline Health facility & 176(88) & $5(28)$ & 1 & \\
\hline Home & $24(12)$ & $1(42)$ & $3.91(0.6-22.5)$ & \\
\hline Level of ANC attendance & & $P<0.0$ & $P<0.8$ & \\
\hline$<6$ visits & $10(95)$ & $3(100)$ & 1 & \\
\hline$\geq 6$ visits & $190(5)$ & $3(15)$ & $0.04(0.0-0.2)$ & $0.03(0.0-0.4)$ \\
\hline Client satisfaction & \multicolumn{4}{|c|}{$P=0.2$} \\
\hline Good & 191(95) & $5(26)$ & 1 & \\
\hline Poor & $9(5)$ & $1(111)$ & $4.7(0.5-44.6)$ & \\
\hline
\end{tabular}

The association of socio-demographic factors, health behaviour's and health care utilization with perinatal outcomes

In table 2, the following factors were found to be associated with adverse perinatal outcome: birth interval less than 24 months (111 per 1000births), gestational age less than 37 weeks (136 per 1000 births) and mothers with less than six antenatal visits (100 per 1000 births). Also, mothers who consumed alcohol, engaged in harmful traditional practices and who never used family planning services, had an increased odds of 5.9, 5.5 and 0.2 respectively of perinatal mortality were also statistically significant. Further analysis revealed that prematurity $\{\mathrm{OR}=1.7, \mathrm{Cl}(1.1-2.2)\}$, harmful traditional practices $\{\mathrm{OR}=1.4, \mathrm{Cl}(0.1-14.8)\}$ and low family planning uptake $\{\mathrm{OR}=1.2, \mathrm{Cl}(0.0-0.7)\}$ appeared significantly associated with perinatal mortality.

The results also showed that women living in a rural area $\{O R=0.41, \mathrm{Cl}(0.1-2.3)\}$ and those delivering at home $\{\mathrm{OR}=3.91$, $\mathrm{Cl}(0.6-22.5)\}$ were more likely to experience adverse perinatal outcomes. Finally, the study found a high perinatal mortality of 33 per 1000 births among mothers aged less than 18 years compared to 18 and 19 years group ( 28 per 1000 births).

\section{DISCUSSION}

In this study all participants were adolescent mothers who have been pregnant as well as experienced still births or delivery at adolescent age with singleton births. For the 200 adolescent mothers interviewed in this study, perinatal mortality rate (PNMR) was 30 per 1000 births slightly lower than the rate of 39 per 1000 births for the northern Ghana ${ }^{7}$ but higher than 22 per 1000 births for the Upper East Region. ${ }^{8}$ PNMR is a key health indicator of the quality of antenatal and perinatal care.

We found in this study that perinatal mortality rate among adolescent mothers who delivered at home was high as compared to their facility counterparts. Some of the reasons for delivering at home were familial and others. In general, it is believed that, the use of health services by women will depend on the availability and also a feeling in the community about where delivery takes place. These findings, though not directly covered during the interview, it might explain the preference for births to take place at home. ${ }^{9}$ Traditional health beliefs of Ghanaian population may also play an important role in the selection of services related to pregnancy, ${ }^{10}$ because they provide something that the formal services do not, which are valued by the mothers, such as 
preference of birthing positions, hot baths after delivery among others. ${ }^{11}$ Understanding these factors is critical to improving the accessibility and utilization of health care by adolescents during pregnancy and childbirth.

To understand how the variables of health behaviour's and healthcare utilization influence perinatal outcomes upon interaction, our study using binary logistic regression found significant predictors of adverse perinatal outcomes with: mothers who had engaged in harmful traditional practices. This finding is consistent with other studies in Ghana ${ }^{12}$ and Tanzania. ${ }^{13}$ There is the need for a stronger role of community-level interventions that target social norms. The following behaviour's had a rippling impact on the perinatal outcomes. Mothers who consumed alcohol during pregnancy, ${ }^{14-16}$ low uptake of family planning ${ }^{12,13,17}$ and mothers who received less than six antenatal visits. ${ }^{18}$

In this study, about thirty percent of the mothers' age between 15 and 17 years. The Upper East Region is noted for a child marriage prevalence of $50 \%$ the highest in Ghana ${ }^{19}$ where a greater number of girls between 15 and 18 years (27 percent) are entering marriage often against their will. ${ }^{20}$

This study found no statistical association between maternal age, residence, marital status, level of education and parity with perinatal morbidity and mortality. This finding is inconsistent with other studies elsewhere. ${ }^{21,22}$ The reason could be attributable to possible uncontrolled confounding risk factors such as smoking and other practices during pregnancies which were not included in this study hence a limitation. A Second limitation is that all adolescents who delivered at home and failed to attend antenatal and child welfare clinics were also not part of this study.

Finally, the ability to recall events by study participants could also be a contributory factor. We suggest that future studies on adolescence and perinatal morbidity and mortality need to approach it from a community's perspective to help address the unmet need for maternal healthcare service utilization for the poor and the specific sub-groups of the population in rural areas.

\section{CONCLUSION}

The results reported in this study indicate that mothers who engaged in harmful traditional practices, used alcohol during pregnancy, never used family planning services prior to their pregnancies had increased odds of experiencing perinatal mortality. The combined effect of these factors need to be taken into account and addressed with a multifaceted approach when counseling women about healthy behaviour before and during pregnancy at health facilities. The disparity in perinatal deaths between rural and urban areas should suggest to policy makers that more needs to be done to attain socio-economic equality in the rural areas particularly in the area of quality, affordable and accessible maternal health services. Also, promoting the use of family planning may ultimately help to foster the utilization of other maternal health services. Programmes that seek to change attitudes that are unfavorable towards maternal and child health services uptake are relevant in these communities. The need for the government to work towards increasing the age at marriage by legislating on marital age. Hence the need to ensure the implementation of the Laws prohibiting child early marriage (Act 560) and forced marriage (Act 554) in Ghana to stop child marriages. Also, greater emphasis is needed on providing adolescents with the skills and sex education to postpone sexual activity until they are able to practice responsible sexual behaviour. Finally, the need to remove the barriers that prevent adolescents from going to the health facility in time by empowering them with decision-making skills regarding childbirth.

\section{REFERENCES}

1. UNICEF. Half a million women die from pregnancy complications each year. Accessed July 24, 2016.

Available at:http://www.wsws.org/en/articles/2009/01/chil-j20.html. 2.WHO.MaternalMortality.Availableat:http://www.who.int/mediacen tre/factsheets/fs348/en/ Accessed February 24, 2016.

3. Ganchimeg T, Mori R, Ota E et al. Maternal and perinatal outcomes among nulliparous adolescents in low- and middleincome countries: a multi-country study. BJOG. 2013, 120 (13): 1622-1630.

4. Weng YH, Yang CY, Chiu YW. Risk Assessment of Adverse Birth Outcomes in Relation to Maternal Age. PLoS One. 2014, 9 (12): e114843-10.1371/journal.pone.0114843.

5. Mukhopadhyay P, Chaudhuri RN, Paul B. Hospital-based perinatal outcomes and complications in teenage pregnancy in India. J Health PopulNutr. 2010, 28 (5): 494-500.

6. Duvan $\mathrm{Cl}$, Turhan NO, Onaran Y, Gümüş I.I., Yuvaci,H, Gözdemir,E. Adolescent Pregnancies: Maternal and Foetal Outcomes.Fatih University, Faculty of Medicine, Department of Obstetrics and Gynecology, Ankara, Turkey. The New Journal of Medicine 2010; 27: 113-116.

7. Engmann $C$, Walega $P$, Aborigo RA et al. Stillbirths and early neonatal mortality in rural Northern Ghana. Trop Med Int Health. 2012 Mar; 17(3):272-82.

8. Ghana Demographic and Health Survey. Accra, Ghana: GSS, GHS, and ICF Macro.2008

9. Jansen I. Decision making in childbirth: the influence of traditional structures in a Ghanaian village. IntNurs Rev. 2006; 53(1):41-6.

10. Engmann CM, Khan S, Moyer CA, Coffey PS, Bhutta ZA.Transformative Innovations in Reproductive, Maternal, Newborn, and Child Health over the Next 20 Years. PLoS Med, 2016, 13(3): e1001969. doi:10.1371/journal.pmed.1001969

11. Dako-Gyeke P, Aikins M, Aryeetey R, Mccough L, Adongo $P B$. The influence of socio-cultural interpretations of pregnancy threats on health-seeking behavior among pregnant women in urban Accra, Ghana.BMC Pregnancy Childbirth. 2013; 13: 211.

12. Welaga $P$, Moyer $C A, A$ borigo $R$ et al. Why are babies dying in the first month after birth? A 7-year study of neonatal mortality in northern Ghana PLoS ONE,2013; 8(3): e58924.doi:10.1371/journal.pone.0058924

13. Krüger C. "Neonatal health in Tanzania - current situation and future outlook" Masters, Curtin University of Technology 2007. Available at: http://carstenkruegernet/attachments/EssayFile/Essay-4-Neonatal-Health [Accessed July 24, 2016].

14. Miranda ML. and Edwards S. Strategic Opportunities for Improving Pregnancy Outcomes in Guilford County, NC. Children's Environmental Health Initiative Nicholas School of the Environment 2009. Duke University, U.S.A

15. Patra J, Bakker R, Irving H, Jaddoe VW, Malini S, Rehm J. Dose-response relationship between alcohol consumption before and during pregnancy and the risks of low birth weight, preterm birth and small for gestational age (SGA)-a systematic review and meta-analyses. BJOG.2011; 118(12):1411-21. 
16. Bakker R, Pluimgraaff LE, Steegers EA et al. Associations of light and moderate maternal alcohol consumption with fetal growth characteristics in different periods of pregnancy: the Generation $\mathrm{R}$ Study. Int J Epidemiol. 2010;39(3):777-89

17. Baiden F, Hodgson A, Adjuik M, Adongo P, Ayaga B, Binka F. Trend and causes of neonatal mortality in the Kassena-Nankana district of northern Ghana, 1995-2002. Tropical Medicine \& International Health 2006, 11: 532-539.

18. Hamilton BE, Martin JA, Sutton PD. Births: Preliminary data for 2002. National vital statistics reports; vol 51 no 11. Hyattsville, Maryland: National Center for Health Statistics. 2003. Availableat:https://www.cdc.gov/nchs/data/nvsr/nvsr51/nvsr51_11. pdf. Accessed July 23, 2016.

19. UNICEF, WHO, The World Bank, The United Nations Population Division. Levels and trends in Child Mortality. Geneva. 2011: UNICEF. Pg 10. Accessed September 3, 2016.

Availableat:http://www.unicef.org/media/files/Child_Mortality_Repo rt_2011_Final.pdf.

20. Ghana Statistical Service, Ghana Health Service, Accra, Ghana, UNICEF, UNFPA, Japan Official Development Assistance, USAID and ICF International, Calverton, Maryland, USA - MICS, 2011.

21. Karlsen S, Say L, Souza JP et al. The relationship between maternal education and mortality among women giving birth in health care institutions: Analysis of the cross sectional WHO Global Survey on Maternal and Perinatal Health. BMC Public Health; 201111:606DOI:10.1186/1471-2458-11-606

22. Sharma V, Katz J, Mullany LC et al. Young Maternal Age and the Risk of Neonatal Mortality in Rural Nepal. Arch Pediatr Adolesc Med. 2008; 162(9): 828-835.

\section{Source of Support: Nil. Conflict of Interest: None Declared.}

Copyright: (c) the author(s) and publisher. IJMRP is an official publication of Ibn Sina Academy of Medieval Medicine \& Sciences, registered in 2001 under Indian Trusts Act, 1882.

This is an open access article distributed under the terms of the Creative Commons Attribution Non-commercial License, which permits unrestricted non-commercial use, distribution, and reproduction in any medium, provided the original work is properly cited.

Cite this article as: Matthew Naakiyab Laari, Alexander Suuk Laar. Exploring Factors Influencing Perinatal Outcomes among Adolescent Pregnancies in Northern Ghana-The Case of Kassena-Nankana Municipality in the Upper East Region. Int J Med Res Prof. 2016; 2(5):75-79. 